\title{
An Analysis and Study on the Adjustment of Indoor Micro- climatic Environment for Traditional Residential Houses in Jiangxi Province
}

\author{
GUO Yang \\ JIangXi Institute of Economic Administors, No. 269 Wolong Road, Nanchang, Jiangxi, China
}

\begin{abstract}
In recent years, with the accelerating pace of human transformation of nature, the depletion of natural resources, the deterioration of the climate and other issues are outstanding, so, green sustainable development has become a hot topic. At present, the domestic design of residential indoor microclimates relies on the adjustment of high energy consumption equipment to meet the needs of the environment, but ignores the appropriate design methods impacting on the living microenvironment, which may reduce energy consumption and achieving sustainable development and creating green buildings as well. This paper takes the Jiangxi area as the research scope, takes the microclimate of the indoor residential environment as the research object, and starts with presentation on the climate characteristics of the hot, rainy and humid Jiangnan climate in Jiangxi Province, combines the morphological characteristics of traditional residential houses and climate regulation behavior in local area for addressing the spatial microclimate, to study and summarize the residential interior design strategies suitable for the climate and environment in the same place, hopefully to provide the basis for improving the microclimate environment of indoor residences.
\end{abstract}

\section{Introduction}

In recent years, with the continuous advancement of urbanization, the requirements from the urban and rural residents for the living environment have changed from basically satisfying the survival needs to creating a more comfortable living environment in the existing large environment. Due to the improvement of economic conditions, people have higher and higher requirements for the living environment, in aspects of size, quality, beauty, comfort, psychological satisfaction and others. With the increase in demand, the development and consumption of natural resources will lead to the depletion of natural resources. Problems such as deterioration of the climate and sharp drop in biodiversity have become more prominent. Especially in recent years, with the rapid development of urbanization, motor vehicle exhaust emissions, industrial waste gas, wastewater pollution and land desertification all have affected the health and life of people in cities. Changes in urban climate affect people's living environment, life safety, and energy consumption in many aspects. As an urban climate cell, the personal residential environment becomes more and more important when the urban population continues to increase. The micro-environment of a city affects the environment of an urban residential community, and the environment of an urban residential community affects the personal residential environment. These three aspects are interrelated and affect each other.
Problems such as heat islands, dry islands, and wet islands that appear in mega cities or larger cities are not only detrimental to the sustainable development of the city, but also aggravating the deterioration of the urban micro-climate environment. In the current situation of continuous extreme climate, with the concept of sustainable development, we, from the angle of personal residence as urban cells, grafted the regulation mode of environmental microclimate in the traditional houses of the south of the Yangtze River into modern interior design to improve people's living environment. This will improve people's awareness in protecting environment by using science and technology, environmental protection materials, and scientific decorative structures, to meet people's comfort and aesthetic requirements, while reducing indoor energy consumption for a green living space.

\section{Factors affecting indoor micro-climate environment}

\subsection{Climate factors}

Jiangxi Province is located in southeastern China, between latitudes $24^{\circ} 29^{\prime} 14^{\prime \prime}$ to $30^{\circ}$ 04'41" and longitudes $113^{\circ} 34^{\prime} 36^{\prime \prime}$ to $118^{\circ} 28^{\prime} 58^{\prime \prime}$. Its warm climate is created by the normal and dominated landforms of mountains and hills, being abundant sun

\footnotetext{
a Corresponding author: author@e-mail.org
} 
shining and abundant rain falling, with the long frostfree period in subtropical humid climate condition.

\subsection{Light}

The average daily radiation in Jiangxi is 97 to $114.5 \mathrm{kcal}$ per square centimeter, in which Duchang County is the most and Tonggu County is the least. The average annual sunshine hours are from 1473.3 hours to 2077.5 hours. Duchang County is the most, while Chongyi County is the least.

\subsection{Air Quality}

Taking the air quality of Jiangxi Province in 2016 as an example, we see the excellent air quality in Nanchang was 318 days, and the excellent or good rate was $86.9 \%$. It ranked first among the capital cities in the central China. The compliance rate of centralized drinking water source and fourteen monitoring sections along Minjiang and Fuhe Rivers is $100 \%$.

\subsection{Humidity}

It is rainy in Jiangxi, with an average annual rainfall of $1341 \mathrm{~mm}$ to $1940 \mathrm{~mm}$. The general performance is less rainfall in the south and the north, more railfall in the east and west, and less in the mountains, more in basins area. Annual precipitation in Wuyi Mountain, Huaiyu Mountain and Jiuling Mountain is as high as $1,800 \mathrm{~mm}$ to $2,000 \mathrm{~mm}$. The average annual precipitation along the Yangtze River, north of Poyang Lake and the Ji Tai Basin is approximately $1350 \mathrm{~mm}$ to $1400 \mathrm{~mm}$. Other areas are between 1500 millimeters and 1700 millimeters.

\subsection{Wind speed}

The average annual wind speed in the province is on meter per second to 3.8 meters per second. The minimum degree is in Dexing City, while the highest degree is in Xingzi County. The average annual windy days range from 0.5 days to 28.5 days, with at least one in Yihuang County and the most in Xingzi County. Poyang Lake, the lower reaches of the Lancang River, the lower reaches of the Fuhe River, the top of the high mountain and the canyon area are rich in wind energy resources. The average annual wind speed is three meters per second to five meters per second.

Based on the natural and geographical environment dominated by mountainous hills in Jiangxi Province, the Jiangnan climate is characterized by abundant sunshine, moist and humidity. In the environment of high temperature, high humidity, calm wind and rain, it gives birth to elegant humanistic atmosphere. This is also reflected in the architectural culture of the south of the Yangtze River, which forms the unique white wall, blue tile, gable and gatehouse.

\section{The adjustment and influence of the spatial distribution of residential buildings on indoor microclimate}

The traditional folk houses in the Jiangxi region are affiliated to the Huizhou architecture. Based on the physical geography and humanities factors in Jiangxi Province, the building features of being against mountains and by rivers, with patches of variously hight, white walls and shingles, are adapted to the characteristics of the wet spring, flood summer, dry autumn and wet winter along the Yangtze River. In the aspect of space layout, building materials, maintenance structure, and environment construction, the problem of shading, ventilation, moisture prevention, heat insulation, and dehumidification of residential buildings was solved, an indoor micro-environment suitable for people's residence was formed, and specific architectural aesthetics on the basis of satisfactory living function was produced.

\subsection{Spatial layout}

Traditional houses in Jiangxi basically follow the same sequence of spatial layout: a courtyard, a gallery, a transitional hall and bedrooms from an outer space to a private space. Different spaces have different functions and aesthetics, regulating the indoor microclimate variously. Each function space enclosed in differently degree, and its physical environment has slight differences. Each space in turn affects each other from the outside to the inside and buffers each other, forming a micro-environment gas field to each other, making people feel comfortable in the entire space.

\subsection{Building Materials}

The structure of traditional folk houses in Jiangxi province is mostly a bucket-type timber frame, with a thin hollow wall or a plastered bamboo wall on the outside, and the walls painted white. The bottom of the wall is often made of masonry stone, and the indoor floor is also paved with slate to protect it from moisture. The wooden parts of the exterior of the house are painted in brown, black, dark green and other colors, and are contrasted with white walls and grey tiles. The colors are mellow and clear, combined with the surrounding natural environment to form picturesque scenery of the water town. The main building materials of traditional houses in Jiangxi are wood, stone, brick, tile, bamboo, ash and other natural materials. The physical properties of these materials are not only good for protecting natural environment, but also good for making the building itself consume less energy, release less carbon.

\subsection{Maintenance structure}

The external maintenance structure of the building is the transitional space from the outdoor natural climate to the indoor micro-climate. The structure includes exterior walls, roofs, exterior windows, corridors and others. It is 
a building structure that directly contacts the indoor natural environment, and plays a role in the summer ventilation while storing heat and resolve dampness in winter. At the same time, under the premise of satisfying the human body comfort, the indoor micro-climate is adjusted to reduce the energy consumption of the building. The external wall is the solid wall part of the building facade. The external walls of traditional houses are mainly composed of three major solid types: solid brick walls, empty fight walls, and brick-wood mixing. The roof is made up in the type of sloping roofs, flat roofs or mixed roofs, mainly composed of brick and wood. The form of doors and windows is mainly panel windows, grille windows, support windows, window exits, double-layer windows, partition doors, door openings matched with hollow carving decoration, and the like. It can meet the shade, ventilation, shelter from the rain, lighting, and effectively regulate the indoor micro-climate. Jiangnan traditional dwellings corridor structure is a semi-open space. From the above, it can be seen that the residential buildings in Jiangxi fully utilize the coordination function of the building inner functional areas from the inside to the outside, and use the natural materials to reduce the energy consumption.

\subsection{Environment Construction}

Based on the superiority of geography and the natural environment, the traditional dwelling houses in Jiangxi Province are mostly immersed in mountains and rivers. The large-scale vegetation environment and living water system create a good local microclimate around the building. The plant's regulation of air is combined with the heat storage of water. When the temperature is high during the daytime, the shade of the plant dissipates heat, the water absorbs heat, wind speed and temperature are adjusted. When the temperature is low at night, the water releases heat and regulates the local microclimate, making up comfortable local climate, in which the village as a residential unit becomes a suitable habitat.

Under normal circumstances, there is a gap for about one meter between residential buildings in Jiangxi, commonly known as cold alleys. The cold alley is composed of brick walls and bluestone. The physical properties of the masonry material make the air to form natural ventilation due to different heating speeds inside and outside the tunnel, so as to have cool ventilation inside tunnel, reducing the heat during the daytime and cooling at night.

Traditional residential areas in Jiangxi have indoor and outdoor greenery vegetation. From the front of the house to the corner of the room, different types of plant change with the seasons, while beautifying the environment. The wet climate in the south is suitable for broad-leaved plants, which improves indoor and outdoor air quality, increasing air humidity and oxygen content, reducing ground temperature and heat radiation, and creating a suitable living environment.

\section{Experience Summary on Indoor Microclimate Environment Design of Traditional Houses in Jiangxi Province}

By analyzing and summarizing the characteristics of traditional dwelling houses in Jiangxi Province, we can find that people have formed a rich architectural experience and wisdom in accordance with natural geographical climate in the course of building development, which is fully manifested in the aspects like site selection, layout, material structure and overall environment of the landforms. In response to the climatic conditions in the Jiangxi region, for the traditional dwelling houses people have adopted different strategies for indoor and outdoor design. In the rainy spring and flood summer, the topography, terrain, and the physical properties of the materials are used to achieve moisture-proof drainage and heat insulation. In winter, sunshine and heat preservation are used to keep heat, and to prevent wind and dampness, so as to create a suitable habitat micro-environment. The design experience of the micro-environment of traditional residential buildings in Jiangxi Province can be summarized into the following aspects:

\subsection{Spatial layout}

The indoor and outdoor micro-climate environmental space layout of residential buildings is divided into two categories: architectural layout and indoor function partition layout. The main climatic factors affecting the layout of buildings are sunshine and wind. These two factors determine the relative locations, azimuth orientations, and layout patterns of individual units in a building group. According to the natural climatic conditions of the region, choosing a suitable building layout can increase the building density and land use efficiency, save energy and protect the environment.

\subsubsection{Layout of buildings in the perspective of sunshine}

(1) Between the arrays of buildings, staggered layouts of the width and depth of the building are adopted, and the buildings are used to obtain sunlight from the side to create a suitable sunshine environment;

(2) In the height of the building, people adopt a layout that is high in the north and low in the south, so as to prevent the high buildings from blocking the sunlight in the low buildings. When the radiation intensity of sunlight is relatively heavy, the space between buildings are appropriately reduced, and a certain amount of shading by the gables between buildings are made use of.

\subsubsection{Attention to ventilation and dampness}

The influence of wind on the microclimate around the building is relatively large. Factors such as regional wind direction, wind speed and wind shadow should be considered in the layout of the building. Studies have shown that cross-shaped building layouts, buildings in 
different heights, can form good ventilation performance, and the impact range of the leeward surface is small, which avoids drastic changes in the wind speed between buildings. And the flow of air formed between the street and the building area can take away heat and spread with pollution.

Jiangxi has cold winters but no heating facilities, while the humidity in the south of the Yangtze River is relatively high, leading to rather coldness in the south. In the south, household heating appliances, such as air conditioners, are generally used, which consumes large amount of electricity. They are costly, and not conducive to long-term ecological energy conservation or environmental protection. In view of the winter climate characteristics and living patterns in the Jiangnan region, the orientation and spacing of residential buildings themselves can play a role in preventing wind and dampness. The layout of the building should be laid in order to decrease the impact of cold wind on the wind ward side in winter. Consequently, the buildng's orientation and space design should be paid attention to, so that the building would has sufficient sunshine in the winter, meanwhile the temperature of every room will be increased.Finally the building can regulate the indoor microclimate to save energy .

In the indoor functional zoning, functional areas such as the master bedroom, children's room, study room and living room all have higher requirements for the thermal environment. Therefore, the solar radiation should be considered in the layout plan, and other areas may be set on the northwestern side. According to people's heat demand in the indoor environment, we may have a reasonable planning suitable for people's living and living habits, and the indoor temperature difference in the building also makes the interior of the room have a dynamic warm trend, creating a relatively stable indoor thermal environment.

\subsection{Decoration Materials}

The use of a large number of natural materials such as stone, wood, brick and clay in traditional houses in Jiangxi provides us with a lesson for our modern architecture. However, it is not enough to stay at the level of traditional building materials. Based on traditional building materials, modern green building materials should be introduced, so the advantages of traditional materials and modern materials are fully combined in walls, heat insulation, waterproof and decoration. This combination avoids either deficiencies, and leads the issue of ecological pollution into a sustainable development path. New building materials include new wall materials, thermal insulation materials, waterproof seal materials and decorative materials. The advantages of these materials are:

(1) Saving or using a small amount of natural raw materials, especially non-renewable resources such as cement, lime, gypsum, clay, and etc.;

(2) Large-scale use of industrial waste (gangue, fly ash, slag, etc.) instead of some or all natural resources to produce wall materials;
(3) Using industrial waste with potential hydraulic properties instead of cement materials;

(4) Saving energy as much as possible in the production process, such as coal, electricity, natural gas, oil, etc.;

(5) Effluent waste, waste gas, waste water, etc. being not emitted, or as little as possible during the production process;

(6) The production of wall products with high quality, good versatility and long service life;

(7) Good characters, convenient construction, high efficiency, low labor intensity of construction, mature construction technology, complete equipment and construction quality being guaranteed;

(8) Composite thermal insulation technology applied to the exterior wall for saving energy and reducing consumption during long-term use;

(9) After the service life of the wall material, it can be recycled, or the waste product can be processed for recycling.

\subsection{Enclosure structure}

The external protective structure is the external wall or surface layer that encloses the building and is directly in contact with the outdoor microclimate environment. It functions as a transition between the indoor microclimate environment and the outdoor microclimate environment. In Jiangxi Province, the transition construction sequence in the traditional houses is a courtyard, a gallery, a hall and bedrooms, while in modern architecture the transitional sequence is exterior walls, roofs, outer windows and bedrooms.

In view of the fact that the climate in Jiangxi Province is hot and rainy in summer, cold and humid in winter, we have to use new environmental protection materials with high strength and good thermal insulation properties for the external walls. At present, China has developed a variety of external wall thermal insulation material systems according to different buildings. Material types can be organically selected and matched. In order to create a comfortable and energy-saving residential building indoor micro-climate, the design of the building envelope should be continued in the following three aspects: first, on the basis of satisfying the comfort of the human body, we have to reduce the energy consumption of the building; second, we have to optimize the design of the building envelope, considering regional climatic factors to regulate multifunctional indoor micro-climate environment; third, we have to use new, green, low-carbon environmental protection materials.

\section{References}

1. Christopher J.Carbon Sequestration: A Comparative Analysis [J].Green Energy and Technology,42 (2010)

2. Gumbs James,Recreating the American Home: The Passive House Approach the Passive House 
Approach[M].Manchester:Mary Low Carbon Prod, (2010)

3. Li Mei,P.N.Rowley.Optimisation of Integrated Low-Carbon Energy Strategies: A Case Study for 'Zero Carbon' Social Housing in the UK[J].Systems and Technologies,265-276 (2011)

4. Life cycle cost implications of energy efficiency measures in new residential buildings $[\mathrm{J}]$. J. Morrissey,R.E. Horne. Energy \& Buildings , 4 ( 2010 )

5. Application research of ECOTECT in residential estate planning $[\mathrm{J}]$. Li Yang,Bao-Jie He,Miao Ye. Energy \& Buildings, (2014)

6. Impact of cold indoor thermal environmental conditions on humanthermal response. Liu Hong,TAN QingLI. Journal of Central South University of Technology English Edition , (2011) 